\title{
Production of antipollutant mask with bamboo based carbon activated using $\mathrm{H}_{3} \mathrm{PO}_{4}$ and $\mathrm{K}_{2} \mathrm{CO}_{3}$
}

\author{
Mahmud Sudibandriyo ${ }^{1, *}$ and Shobrun Jamil ${ }^{1}$ \\ ${ }^{1}$ Department of Chemical Engineering, Universitas Indonesia, Depok, Indonesia
}

\begin{abstract}
The increase of developing countries' economic level has led to increase in air pollution problem. This research aims to make activated carbon based gas mask filter that was prepared from bamboo scraps by the combined activation using $\mathrm{H}_{3} \mathrm{PO}_{4}$ and $\mathrm{K}_{2} \mathrm{CO}_{3}$. Bamboo was selected as raw material because of its abundant availability and high cellulose content (42.4-53.6\%).Dip coating was conducted to coat activated carbon on the surface layer of mask by adding TEOS compound.Furthermore, adsorption capacity of activated carbon was tested using compartment by flowing air containing $\mathrm{CO}$ and $\mathrm{CO}_{2}$ for one hour. The results of the characterization shows that the iodine number of the activated carbon produced reaches $916.3 \mathrm{mg} / \mathrm{g}$ with BET surface area of $465.2 \mathrm{~m}^{2} / \mathrm{g}$. SEM-EDX analysis shows that the carbon content is $74.83 \%$ wt.Adsorption capacity of activated carbon was tested using compartment by flowing air containing pollutant gas and compressed air for one hour. The results indicate that the maximum number of moles $\mathrm{CO}_{2}$ adsorbed is 4.8 $\mathrm{mmol} / \mathrm{g}$ with 7 hour saturated time, while adsorption capacity of CO measured in 1 hour test is $0.103 \mathrm{mmol} / \mathrm{g}$. Therefore, activated carbon has met the standards and can be applied for gas mask filter to eliminate $\mathrm{CO}$ and $\mathrm{CO}_{2}$ until below safety limit concentration.
\end{abstract}

\section{Introduction}

The level of air pollution in big cities has exceeded the safety limits. The substances emitted from motor vehicle such as suspended particulate matter (SPM), NOx, SOx, and $\mathrm{COx}$ are toxic and very harmful for human health. Among of these hazardous substances, $\mathrm{CO}$ and $\mathrm{CO}_{2}$ has the greatest composition on motor vehicle emissions. Along with the increasing emission of air pollutant gas, it is necessary to prevent the bad aspects on health.

One of the prevention ways to reduce air pollution is via adsorption by using activated carbon based gas mask filter. Additional activated carbon in the mask will give better performance since it can adsorb both of particulate matters and pollutant gases. Activated carbon is a porous material that behaves as a powerful adsorbent because of high surface area, adequate pore size distribution, and relatively high mechanical strength [1]. In this case, bamboo is one of agricultural biomass waste that has potential to be used as a raw material for the production of activated carbon. It is because bamboo has high lignocellulose content (approximately 53.6\% cellulose and $26.6 \%$ lignin) [2]. Activated carbon was prepared by combined activation using $\mathrm{H}_{3} \mathrm{PO}_{4}$ and $\mathrm{K}_{2} \mathrm{CO}_{3}$ and continued by heating in the furnace until $750^{\circ} \mathrm{C}$. Furthermore activated carbon was coated on the mask filter by adding TEOS compound. Several characterization and adsorption test were used to obtain the performance of activated carbon produced

\section{Methodology}

\footnotetext{
* Corresponding author: msudib@che.ui.ac.id
}

Methods applied in this study was started by activated carbon preparation and characterization then continued by adsorption test.

\subsection{Adsorbent Preparation}

Bamboo scraps were collected from Banten, Indonesia. They were crushed to a particle size of 30 mesh, washed with distilled water to remove surface dirt then dried in oven at $100^{\circ} \mathrm{C}$ until the weight is constant. A certain amount of raw material was soaked with $40 \%$ at the impregnation ratio (the mass ratio of $\mathrm{H}_{3} \mathrm{PO}_{4}$ to bamboo) of $3: 1$. The mixture was dehydrated in an oven at $80^{\circ} \mathrm{C}$ for $12 \mathrm{~h}$. The dehydrated sample was placed in a stainless steel tubular reactor and heated to $450^{\circ} \mathrm{C}$ under a nitrogen flow of $40 \mathrm{~cm}^{3} / \mathrm{min}$ for $0.5 \mathrm{~h}$. The obtained sample was washed with distilled water and $\mathrm{NaOH} 0.1 \mathrm{~N}$ until the $\mathrm{pH}$ of filtrate became 6.8 .

The dried sample obtained by $\mathrm{H}_{3} \mathrm{PO}_{4}$ activation was mixed with a saturated $\mathrm{K}_{2} \mathrm{CO}_{3} 20 \%$ at the mass ratio between $\mathrm{H}_{3} \mathrm{PO}_{4}$ and bamboo $3: 1$. The mixture was dehydrated in an oven at $50^{\circ} \mathrm{C}$ for $12 \mathrm{~h}$. Then, dehydrated sample was heated to $750^{\circ} \mathrm{C}$ and stayed at a specified temperature for $0.5 \mathrm{~h}$ under a nitrogen flow of $40 \mathrm{~cm}^{3} / \mathrm{min}$. The final products were washed with distilled water and $\mathrm{CH}_{3} \mathrm{COOH} 0,1 \mathrm{~N}$ until the $\mathrm{pH}$ of filtrate 7 and dried in the oven to release the moisture content. Furthermore for coating process, 6 gram of activated carbon was dissolved on solution containing $100 \mathrm{~mL}$ water and $1 \mathrm{~mL}$ TEOS.

Coating solution was stirred by hot plate magnetic stirrer at $85^{\circ} \mathrm{C}$ for 30 minutes. Flannel was dipped several times in coating solution for 10 minutes and then being dried on oven at $120^{\circ} \mathrm{C}$ for 4 hours before added to mask. 


\subsection{Characterization}

The surface area of activated carbon was determined by Brunauer-Emmett-Teller (BET) and iodine number. Scanning electron microscopy (SEM) and Energy Dispersive X-ray (EDX) was done to identify the surface structure and composition of the activated carbon atoms. EDX is integrated with SEM. The instrument of SEMEDX used is from JEOL.

\subsection{Adsorption Test}

Adsorption test was conducted in compartment shown in Fig 1, aimed to observe the effect of initial $\mathrm{CO}$ and $\mathrm{CO}_{2}$ concentration to adsorption performance. Two pollutant gases used in this test were $\mathrm{CO}$ and $\mathrm{CO}_{2}$. Each gases had been mixed with compressed air before entered the compartment The test is carried on for 1 hour for each inlet concentration variant $(250,500,750 \mathrm{ppm}$ for $\mathrm{CO}$ and 2000, 2500, $3000 \mathrm{ppm}$ for $\mathrm{CO}_{2}$ ). Both of compressed air and pollutant gas were controled by check valve, and flowmeter. Flowmeters were adjusted until reached the desired initial concentration. Check valves were used for keeping each flow stable and preventing back flow. The gas flows through section $\mathrm{B}$ because driven by exhaust fan. Between section A and B activated carbon mask were placed, and final concentration of pollutant gas was measured by analyzer in section B.

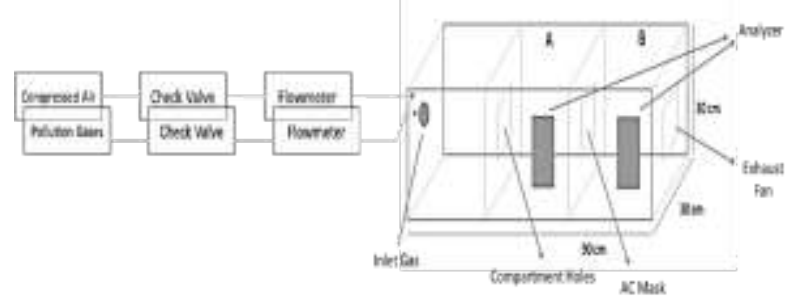

Fig. 1. Schematic diagram of the adsorption test

The amount of adsorbed gas was determined by:

$$
\text { \%adsorption }=\frac{C_{\text {in }}-C_{\text {out }}}{C_{\text {in }}} \times 100 \%
$$

Where $C_{\text {in }}$ is initial concentration and $C_{\text {out }}$ is final concentration of gas. Furthermore, the adsorption capacity of activated carbon for each $\mathrm{CO}$ and $\mathrm{CO}_{2}$ gases were determined by Equation 2 [3].

$$
F_{\text {in }} . C_{\text {in }}-F_{\text {out }} \cdot C_{\text {out }}=\frac{d(q \cdot W)}{d t}
$$

Where:

$$
\begin{array}{lll}
\mathrm{F}_{\text {in }} & =\text { inlet gas flow rate } & (\mathrm{mL} / \mathrm{min}) \\
\mathrm{F}_{\text {out }} & =\text { outlet gas flow rate } & (\mathrm{mL} / \mathrm{min}) \\
\mathrm{C}_{\text {in }} & =\text { inlet gas concentration } & (\mathrm{ppm}) \\
\mathrm{C}_{\text {out }} & =\text { outlet gas concentration } & (\mathrm{ppm}) \\
\mathrm{q} & =\text { amount of gas adsorbed } & (\mathrm{mg} / \text { gram adsorbent }) \\
\mathrm{W} & =\text { adsorbent weight } \quad(\mathrm{gram})
\end{array}
$$

\section{Result and Discussion}

\subsection{Characterization}

Activated carbon produced has iod number $916 \mathrm{mg} / \mathrm{g}$, equivalent to $1165 \mathrm{~m}^{2} / \mathrm{g}$. The surface area produced from iod number calculation approach the Langmuir surface area i.e. $957.6 \mathrm{~m}^{2} / \mathrm{g}$.

In the other hand, BET surface area is $465.2 \mathrm{~m}^{2} / \mathrm{g}$. Compared with the study of activated carbon from bamboo before, BET surface area is relatively small [3]. This conjecture for this small surface area is because the chemical substance that was used for neutralizing $\mathrm{pH}$ would act as impurities and prevent the pore to be opened. The EDX test result shows that activated carbon consist of $74.83 \%$ wt carbon. According to Sridhar et al, the raw bamboo has about $10 \%$ fixed carbon [4]. The increasing number of carbon are caused by the activation process. Activation, especially heating up in the furnace removes the impurities rather than carbon. The more carbon content, the better of activated carbon. Fig. 2 and Fig. 3 show the morphology of the activated carbon in $1500 \mathrm{x}$ and 3000x magnification respectively.

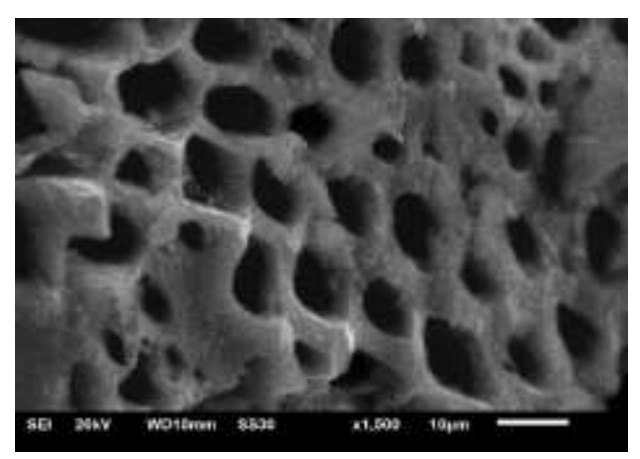

Fig. 2. SEM micrograph (1500X)

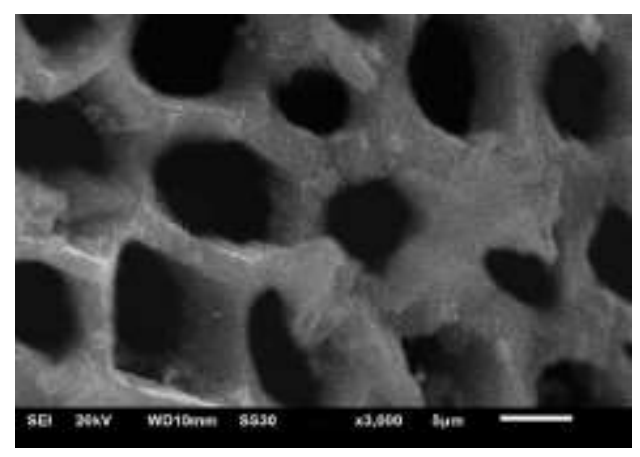

Fig. 3. SEM micrograph (3000X)

Scanning electron microscopy (SEM) is widely used to study the surface morphology, including pore structure and pore arrangement on a material surface. As seen in Fig 2 and 3, the whole process of activation were effective in creating high surface area with well-developed pores on the surface of activated carbon, although there are still several dirty molecules covering up the pores. More amount of demineralized water would be needed to clear off the dirt. 


\subsection{Adsorption Test}

Results for $\mathrm{CO}$ and $\mathrm{CO}_{2}$ adsorption test is graphically shown by Fig. 4 and 5 .

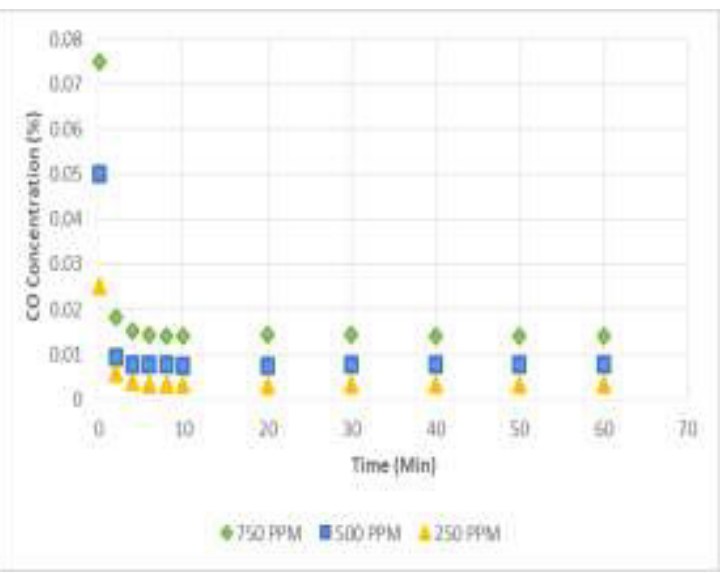

Fig. 4. Effect of increased inlet for $\mathrm{CO}$ adsorption

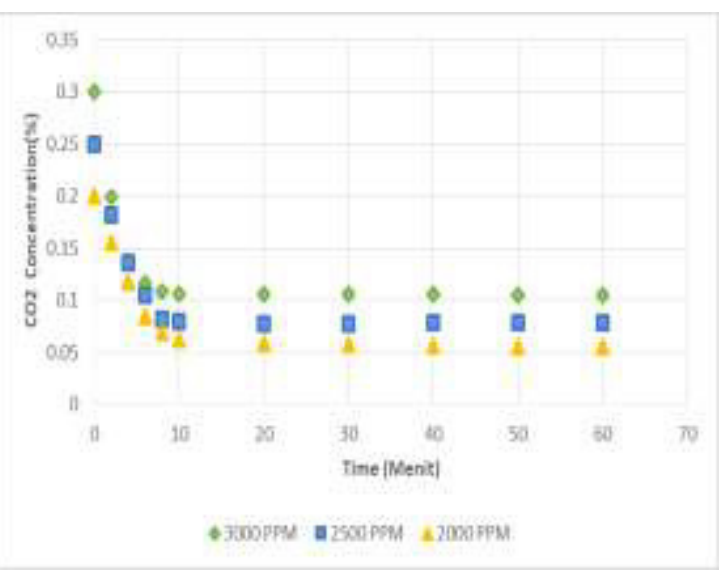

Fig. 5. Effect of increased inlet for $\mathrm{CO}_{2}$ adsorption

Fig. 4 and 5 indicates that the activated carbon mask remains capable to adsorb both $\mathrm{CO}$ and $\mathrm{CO}_{2}$ despite an increase in initial concentration. It appears that the final concentration increases with the increasing initial concentration. This can be explained by Langmuir adsorption model that in equilibrium condition, the amount of total gas adsorbed per unit weight of solid will remain constant, indicating that the entire area of activated carbon has been fully occupied by gas. Thus the increasing initial concentration will reach a condition where activated carbon become saturated and causing the concentration of gas leaving the mask become higher. It is proven in this research for the initial $\mathrm{CO}_{2}$ concentration $2000 \mathrm{ppm}$, the mask is capable to reduce $72.15 \% \mathrm{CO}_{2}$ with final concentration $557 \mathrm{ppm}$ while at concentration $3000 \mathrm{ppm}$, the mask is only capable to reduce $64.83 \%$ $\mathrm{CO}_{2}$. These results are slightly better than those obtained by Nazif et $a l$, where his activated carbon capability reducing $\mathrm{CO}_{2}$ are $70 \%$ and $62.53 \%$ for concentration 2000 and $3000 \mathrm{ppm}$ respectively [5]. This is reasonable, because BET surface area in this research is higher than that obtained in Nazif work $\left(432.26 \mathrm{~m}^{2} / \mathrm{g}\right)$.
Furthermore, saturated time measurement for $\mathrm{CO}_{2}$ adsorption was conducted under initial concentration of $\mathrm{CO}_{2} 2000$ ppm as shown in Fig 6.

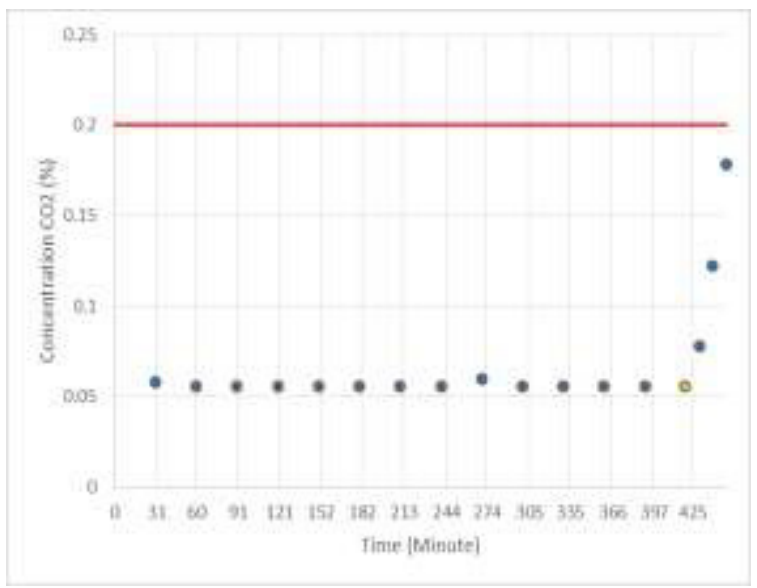

Fig. 6. $\mathrm{CO}_{2}$ saturated time measurement

It shows that the activated carbon mask becomes saturated over a span of time between 420-430 minutes (approximately 7 hour). A large concentration will speed up the saturated process of activated carbon as more pores of activated carbon adsorb $\mathrm{CO}_{2}$. In addition, the amount of activated carbon and TEOS attached to this activated carbon mask is 0.88 grams, relatively small amount thus accelerating the saturated process of activated carbon. Based on saturated time, the adsorption capacity for $\mathrm{CO}_{2}$ is calculated using Equation 2 and tabulated in Table 1.

Table 1. $\mathrm{CO}_{2}$ Adsorption Capacity

\begin{tabular}{|c|c|c|}
\hline $\begin{array}{c}\text { Time } \\
(\mathbf{m i n})\end{array}$ & $\begin{array}{c}\mathbf{C O}_{2} \\
\text { Outlet (ppm) }\end{array}$ & $\begin{array}{c}\mathbf{C O}_{2} \text { Adsorption } \\
(\mathbf{m m o l} / \mathbf{g})\end{array}$ \\
\hline 30 & 578 & 0.339 \\
\hline 60 & 557 & 0.344 \\
\hline 90 & 555 & 0.345 \\
\hline 120 & 558 & 0.344 \\
\hline 150 & 556 & 0.345 \\
\hline 180 & 555 & 0.345 \\
\hline 210 & 558 & 0.344 \\
\hline 240 & 557 & 0.344 \\
\hline 270 & 600 & 0.334 \\
\hline 300 & 559 & 0.344 \\
\hline 330 & 557 & 0.344 \\
\hline 360 & 556 & 0.345 \\
\hline 390 & 556 & 0.345 \\
\hline 420 & 555 & 0.345 \\
\hline \multicolumn{2}{|r|}{$\mathrm{CO}_{2}$ Adsorption Capacity } & 4.806 \\
\hline
\end{tabular}

The result shows that for $\mathrm{CO}_{2}$, the mask has adsorption capacity $4.806 \mathrm{mmol} \mathrm{CO}_{2} /$ gram AC. This is the maximum adsorption capacity that the mask can 
adsorbed because it was calculated until it reach equilibrium condition. This $\mathrm{CO}_{2}$ adsorption capacity value is closed to the value obtained by Sudibandriyo, et al. [6]. Moreover, adsorption capacity for $\mathrm{CO}$ is measured for 1 hour test long, having value of $0.103 \mathrm{mmol} / \mathrm{gram} \mathrm{AC}$ as tabulated in Table 2.

Table 2. CO Adsorption Capacity for $1 \mathrm{~h}$

\begin{tabular}{|c|c|c|}
\hline $\begin{array}{c}\text { Time } \\
\text { (min) }\end{array}$ & $\begin{array}{c}\text { CO } \\
\text { Outlet (ppm) }\end{array}$ & $\begin{array}{c}\text { CO Adsorption } \\
\text { (mmol/g) }\end{array}$ \\
\hline 10 & 33 & 0.0172 \\
\hline 20 & 31 & 0.0174 \\
\hline 30 & 32 & 0.0173 \\
\hline 40 & 33 & 0.0172 \\
\hline 50 & 33 & 0.0172 \\
\hline 60 & 32 & 0.0173 \\
\hline \multicolumn{2}{|c|}{ CO Adsorption Capacity } & 0.1036 \\
\hline
\end{tabular}

The prescribed safety limit for $\mathrm{CO}$ and $\mathrm{CO}_{2}$ should not exceed 9 and $5000 \mathrm{ppm}$. Based on Devita, et al. $\mathrm{CO}$ and $\mathrm{CO}_{2}$ concentration on the road has an average of 10.6 and $973.2 \mathrm{ppm}$, respectively [7]. From percentage of elimination showed in Fig. 4 and 5, it is known that this activated carbon mask can be applied to eliminate $\mathrm{CO}$ and $\mathrm{CO}_{2}$ gases below the safety limit. Furthermore, the production of antipollution mask from bamboo is very potential to be scaled up by increasing production capacity and creating comfortable design for consumer.

\section{Conclusion}

The BET surface area of the activated carbon from bamboo is $465.18 \mathrm{~m}^{2} / \mathrm{g}$. SEM characterization shows that the whole process of activation were effective in creating high surface area with well-developed pores on the surface of activated carbon. Activated carbon has been successfully coated on the mask using TEOS adhesive. This mask can eliminate pollutant gases with adsorption capacity $0.103 \mathrm{mmol} \mathrm{CO} /$ gram $\mathrm{AC}$ and $4.806 \mathrm{mmol} \mathrm{CO}_{2} /$ gram AC. Based on the results, it can be conclude that the produced activated carbon can be used in a gas mask filter production to overcome air pollution problem.

The author would like to thank all parties that have supported this study, especially Universitas Indonesia via Grant of International Publication Indexed for Thesis of UI's Students or known as PITTA 2018 (2437/UN2.R3.1/HKP.05.00/2018).

\section{References}

1. A. Chafidz, W. Astuti, D. Hartanto, P.P. Sari, A.S. Mutia, Proceeding of the $2^{\text {nd }}$ International Conference on ICET4SD, 154 (2017).

2. Krisdianto, G. Sumarni, A. Ismanto, Sari Hasil Penelitian Bambu, Pusat Penelitian Hasil Hutan, Badang Litbang Kehutaan dan Perkebunan Bogor, 29 (2000)

3. Siriwardane RM., Shen E., Fisher J., Poston, A. Shamsi. www.netl.doe.gov (2001).
4. G. Sridhar, D.N. Subbukrishna, S. Dasappa, P.J. Paul, H.S. Mukunda, Torrefaction of Bamboo, The $15^{\text {th }}$ European Biomass Conference \& Exhibition (2007).

5. F. Nazif, M. Sudibandriyo,The $2^{\text {nd }}$ International Conference on ICET4SD, 154 (2017).

6. M. Sudibandriyo, et al, Langmuir, 19, 5323-5331 (2003).

7. N. Devita, T. Joko, Jurnal Kesehatan Masyarakat, 5, 367 (2017).

8. Y. Wang,f H. Ngo, W. Guo, Sci. Total Environ., 533, 32-39 (2015)

9. M. Lillo-Rodenas, D. Cazrola-Amoros, A. LinaresSolano, F. Beguin, C. Clinard. J. Rouzaud. Carbon, 42(7), 1305 - 1310 (2004). 